\title{
The U-tube: A New Paradigm for Borehole Fluid Sampling
}

by Barry Freifeld

doi:10.2204/iodp.sd.8.07.2009

\section{Introduction}

Fluid samples from deep boreholes can provide insights into subsurface physical, chemical, and biological conditions. Recovery of intact, minimally altered aliquots of subsurface fluids is required for analysis of aqueous chemistry, isotopic composition, and dissolved gases, and for microbial community characterization. Unfortunately, for many reasons, collecting geofluids poses a number of challenges, from formation contamination by drilling to maintaining integrity during recovery from depths. Not only are there substantial engineering issues in retrieval of a representative sample, but there is often the practical reality that fluid sampling is just one of many activities planned for deep boreholes. The U-tube geochemical sampling system presents a new paradigm for deep borehole fluid sampling.

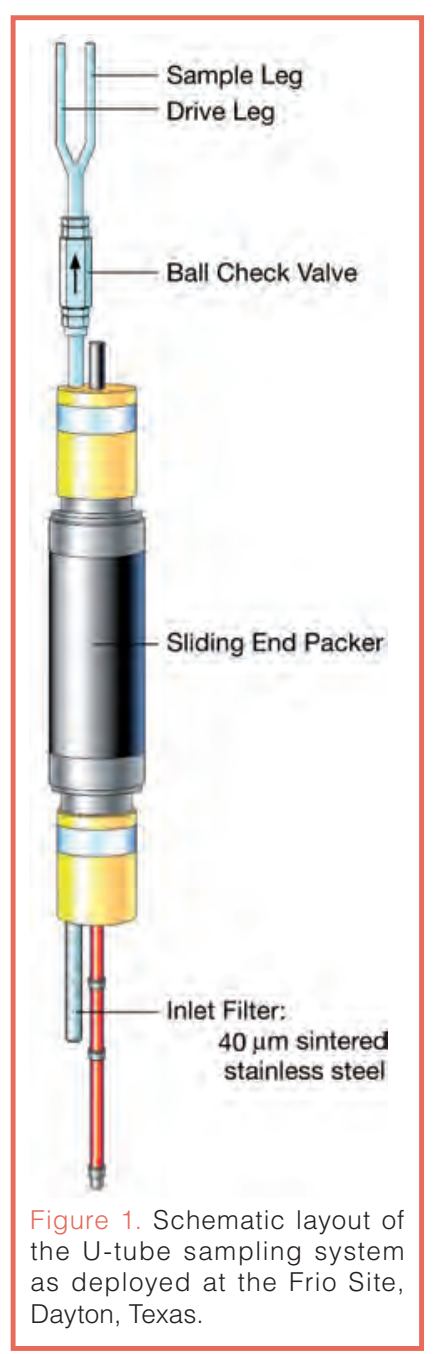

Because the system is small, its ability to integrate with other measurement systems and technologies opens up numerous possibilities for multifunctional integrated wellbore completions. To date, the U-tube has been successfully deployed at four different field sites, each with a different deployment modality, at depths from $260 \mathrm{~m}$ to $2 \mathrm{~km}$. While the U-tube has proven to be highly versatile, these installations have resulted in data that provide additional insights for improving future U-tube deployments.

\section{The U-Tube}

The U-tube sampler is a simple positive fluid displacement pump which uses a high pressure gas drive. Wood (1973) demonstrated this methodology for shallow vadoze zone sampling using a porous cup inlet. Figure 1 shows a schematic of the U-tube sampler as configured for installation beneath a wellbore packer. The heart of the U-tube is the ball check-valve, which contains the only moving part of the sampling system in the borehole. A loop of tubing that terminates at the surface forms the "U". The check-valve is located beneath a "tee" at the base of the $\mathrm{U}$ and it permits fluid to enter the loop but closes (by application of gas from the surface) when pressure in the $U$ is increased above hydrostatic. A sintered stainless steel filter terminates the inlet beneath the check-valve to prevent the check-valve from plugging.

To collect a sample, the $U$ is first filled by venting the sample and drive legs to the atmosphere, thus allowing fluid to rise to the formation hydrostatic level. The sample is recovered by supplying high-pressure $\mathrm{N}_{2}$ (or another inert gas) to the drive leg, closing the check-valve, and forcing fluid out of the sample leg. While conceptually the U-tube is straightforward, the ability to independently control pressures on both the drive and sample legs presents numerous options for collecting and processing of fluids at the surface. By repeating sample collection cycles, the borehole fluid can be flushed and fresh fluid pulled in from the formation. The volume of the sample depends on the formation pressure as well as the diameter and wall thickness of the tubing used, but for an installation at a depth of $1 \mathrm{~km}$, a $6 \mathrm{~mm}$ or $9 \mathrm{~mm}$ diameter tube with a $1.2 \mathrm{~mm}$ wall thickness has a U-tube volume of $20 \mathrm{~L}$ or $68 \mathrm{~L}$, respectively.

\section{The Frio Brine Pilot- $-\mathrm{CO}_{2}$ Storage and Multiphase Fluids}

The Frio Brine Pilot was the first deep borehole application in which I deployed a positive displacement pump incorporating small diameter tubing and a check-valve. The Frio Brine Pilot, Dayton, Texas, was a demonstration program for the geosequestration of $\mathrm{CO}_{2}$ in saline aquifers led by the Texas Bureau of Economic Geology (Hovorka et al., 2006). In September 2004, 1600 t of $\mathrm{CO}_{2}$ were injected into the Frio Sandstone at a depth of $1.5 \mathrm{~km}$ over a span of ten days. A second experiment conducted in 2006 at the same site consisted of an injection of $350 \mathrm{t}$ of $\mathrm{CO}_{2}$ in sand at a depth of $1.6 \mathrm{~km}$. The objectives of the Frio Brine Pilot tests included understanding the hydrological and geochemical impact of the $\mathrm{CO}_{2}$ on the subsurface and evaluation of various monitoring tools that would inform us as to the shape and distribution of the $\mathrm{CO}_{2}$ plume. In addition to surface and cross-hole 
seismic monitoring, we used fluid sampling from an observation well placed $30 \mathrm{~m}$ up-dip from an injector well to determine changes in the geochemistry as the plume swept past, and interpret the arrival of added tracers.

The constraints on the fluid sampling program were many. We had to do the following:

- Minimize impact on the flow-field

- Permit wireline logging operations

- Coexist with other downhole sensors, which included a tubing deployed seismic source, a string of hydrophones, and a pressure/temperature sensor

- Conduct frequent (hourly) sampling

- Allow for on-site real-time analysis of $\mathrm{pH}$, alkalinity, and gas composition

- Enable functioning in a water-only, gas/water, or gas-only system

- Accurately determine the ratio of supercritical $\mathrm{CO}_{2}$ to formation brine in the sampled fluid

The standard sampling technologies that were considered and rejected included electrical submersible pumps (unable to operate in two-phase systems), wire-line deployed flow-through samplers (unable to operate at high frequency during a 24-hour-a-day, multi-week experiment), and gas lifting (it would be difficult to control the flow rate, and the large volumes produced would disturb the flow-field. It would also be difficult to interpret downhole gas chemistry because of the large volume of lifting gas.).

The Frio Brine Pilot U-tube design consisted of a loop of $3 / 8^{\prime \prime} \times 0.049^{\prime \prime}$ wall $316 \mathrm{~L}$ stainless steel tubing, which at a depth of $1.5 \mathrm{~km}$ contains a volume of $118 \mathrm{~L}$. Four $13 \mathrm{~L}$ high pressure stainless steel cylinders were used to store the sampled fluid on the surface for analysis. The U-tube control lines and other instruments were strapped onto production tubing using cable protectors (Cannon Services Ltd., Stafford, Texas, U.S.A.). To isolate the perforated interval in the $5 \frac{1}{1} 2^{\prime \prime}$ casing, a pneumatic packer with feedthroughs to accommodate various lines was located at the base of $27 / 8$ " production tubing. From a geochemical sampling standpoint, it would have been best to locate the bottom of the packer just above the top perforation, minimizing the volume below the packer. However, to accommodate logging operations, the packer was set $14.3 \mathrm{~m}$ above the top perforation. The inlet port to the U-tube-a sintered stainless cylinder $(60 \mathrm{~cm}$ long × $19 \mathrm{~mm}$ diameter, $40 \mu \mathrm{m}$ pore size; Mott Corporation, Farmington, Conn., U.S.A.) - was located $30 \mathrm{~cm}$ below the bottom of the packer. The volume of the cased interval between the bottom of the packer and the top of the perforations was $177 \mathrm{~L}$, with the $6.1 \mathrm{~m}$ perforated interval having an additional 75.4 L volume. Every two cycles of the U-tube would purge a volume equal to the dead-space between the top of the perforated interval and the U-tube inlet.

In contrast to the simplicity of the downhole U-tube system, the surface processing of the recovered fluids was quite complex. The U-tube surface completion consisted of six different manifold assemblies, allowing for careful control of sampling conditions and complete system purging between samplings. To facilitate reproducible sampling and minimize the potential for operator error, the sampling operation was automated with pneumatically operated valves. Control software was developed using the graphical programming language Labview (National Instruments, Austin, Texas, U.S.A.). Figure $2 \mathrm{~A}$ shows the four $13 \mathrm{~L}$ sample vessels along with associated valving and gauges, with strain gauges mounted at the base of each cylinder to measure the bulk
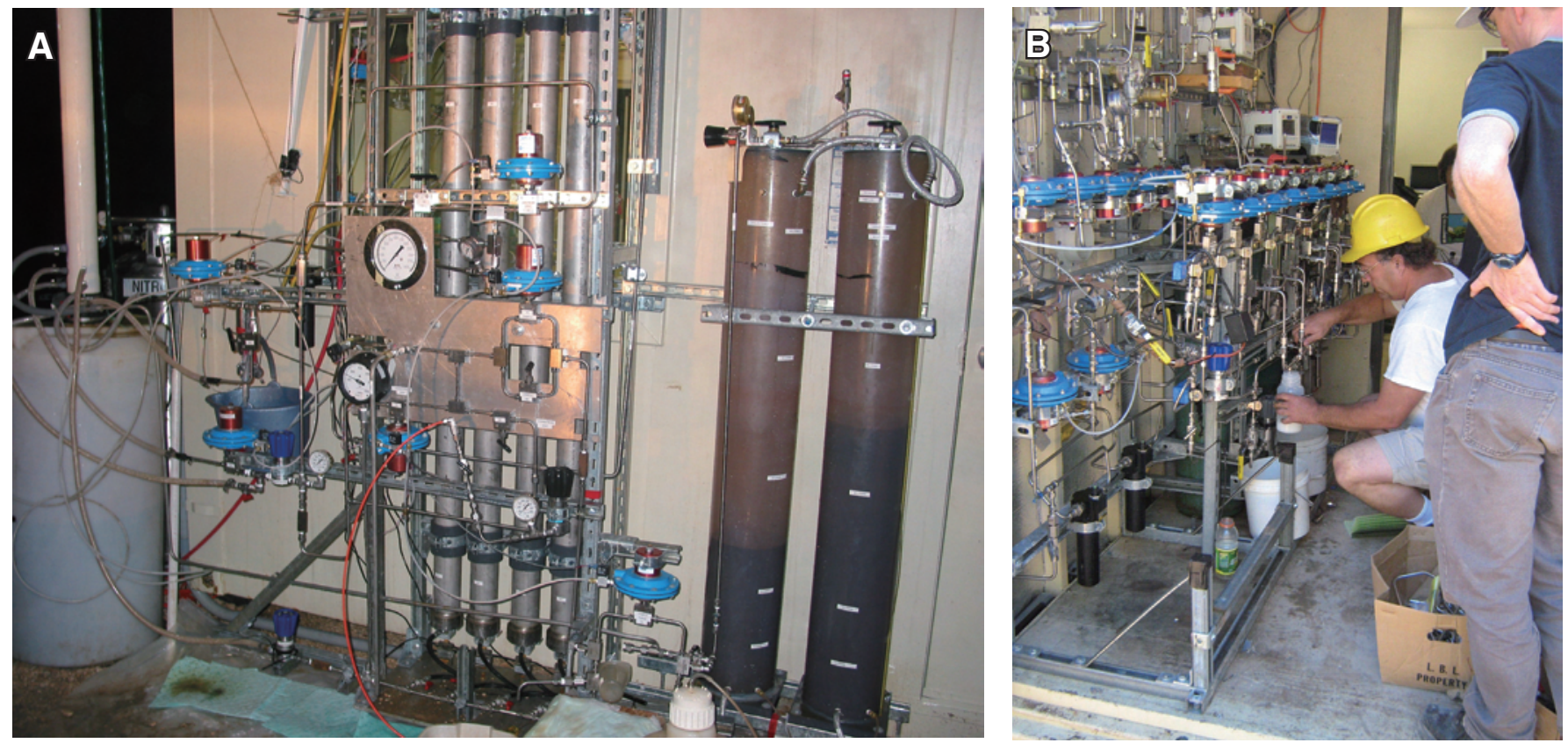

Figure 2. The Frio Brine Pilot surface sampling systems: [A] Four $13 \mathrm{~L}$ high pressure sample vessels mounted in sliding sleeves and resting on strain gauges to measure fluid density. [B] Computer-operated valve manifolds used to operate the U-tube samplers. 
density of the sampled fluid. Figure $2 \mathrm{~B}$ shows the bank of automated valves needed to operate the various manifolds. Lifting the water from the sampling interval to the ground surface via the U-tube and collecting and analyzing the samples involved an eight-step process described in detail in Freifeld et al. (2005). In short, the process consists of (1) filling the U-tube with borehole fluid by venting the drive and sample legs to the atmosphere; (2) purging the gas sample manifold, sample vessels, and liquid sample manifold with $\mathrm{N}_{2}$ gas to remove any residual fluid from these systems prior to sampling; (3) bleeding down the $\mathrm{N}_{2}$ to atmospheric pressure inside all of the process tubing and sample vessels; (4) evacuating the $\mathrm{N}_{2}$ from the sample cylinders; and (5) charging the U-tube drive leg with $\mathrm{N}_{2}$ to close the downhole check-valve and force fluid to the surface (steps 6-8 described below). The first 20-25 L of fluid produced from the sample leg was discarded because it was considered potentially phase-segregated. At the end of Step 5, bulk samples were collected from the sample leg in small, transportable high-pressure cylinders for later laboratory analysis, as well as in open containers for immediate on-site measurement of $\mathrm{pH}$ and alkalinity. Step (6) consisted of directing the sample fluid from the sample line into the evacuated high-pressure cylinders until a pressure gauge indicated that the cylinders were at formation pressure. The final two steps consisted of (7) directing a gas sample from the top of the sample cylinders to a quadrupole mass spectrometer (Omnistar, Pfeiffer Vacuum Technology, Nashua, N.H., U.S.A.) and (8) $\mathrm{N}_{2}$ purging the remaining fluid from the U-tube, so that it could repeat the cycle for the next sample.

Some problems arose during the operation.

1. Hydrate formation and freezing occurred at some of the vent values because of Joule-Thompson cooling.

2. The large volumes of gases and high moisture and salt content bypassed various collection systems and disabled rotary vane and oil-based vacuum pumps.

3. The carefully developed automated sampling routines had to be modified as gas contents increased and system behavior changed.

In the end, it was learned that leaving the sample vessels filled with $\mathrm{N}_{2}$ at one atmosphere both eliminated the complex evacuation cycle and facilitated the accurate estimation of dissolved gas concentration, by acting as a known reference standard (Freifeld and Trautz, 2006). The combination of limiting the pressure drop across vent valves and using heat lamps and heat trace tape stopped the formation of blockages in the system.

Despite considerable difficulty in keeping the complex system operating, forty-two aqueous samples were acquired over the first fifty-two hours of sampling, and rapid changes in geochemical conditions were observed as the $\mathrm{CO}_{2}$ plume traversed the monitoring well (Kharaka et al., 2006). Figure 3 shows the gas composition for $\mathrm{CO}_{2}, \mathrm{O}_{2}$, Ar, and $\mathrm{CH}_{4}$ measured

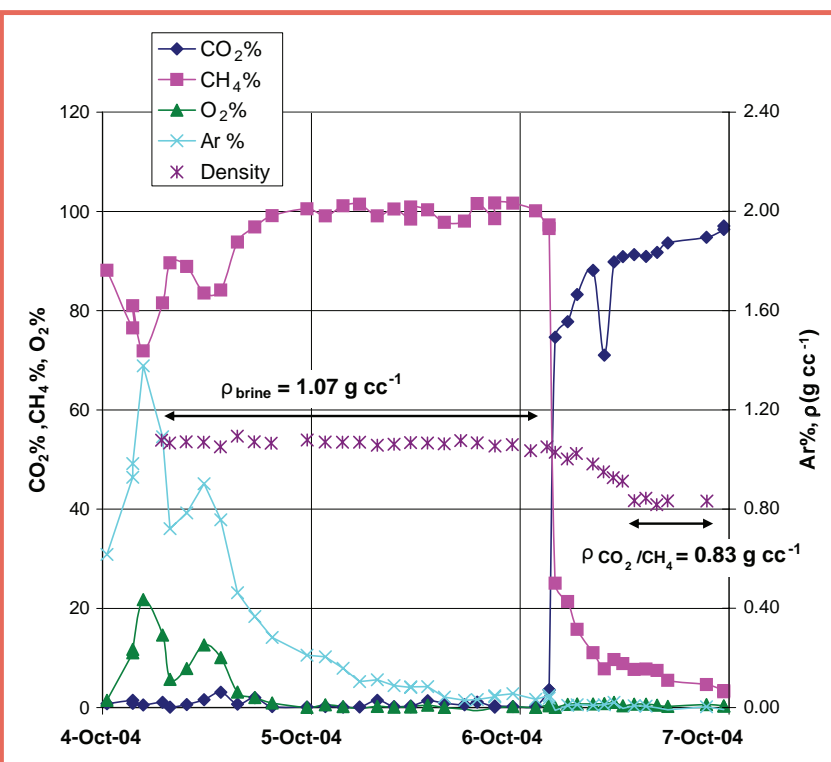

Figure 3. Frio Brine Pilot geofluid sample gas composition and density. Note that the presence of oxygen is indicative of atmospherically contaminated well-workover fluids.

on the quadrupole spectrometer, as well as sample fluid density. The presence of $\mathrm{O}_{2}$ is an indicator of contamination with workover fluids that had equilibrated with air, and is not naturally found in the highly reducing environment of the Frio brine. Eventually, the sample streams changed from liquid to predominantly supercritical $\mathrm{CO}_{2}$, and the self-lifting U-tube no longer needed compressed $\mathrm{N}_{2}$ to drive the sample to the surface. While the system was self-lifting, the sample cylinders (based upon their known volume and measured pressure) were used to quantify the gas withdrawn from the ground and to estimate the time at which the gas entered the U-tube from the formation. The tracer travel times from the injection well to the U-tube sampler were used to estimate the formation $\mathrm{CO}_{2}$ saturation. A geochemical interpretation of the rock-brine- $\mathrm{CO}_{2}$ interaction has been presented by Kharaka et al. (2006), and a discussion on the quadrupole mass spectrometer methodology can be found in Freifeld and Trautz (2006).

\section{Further Borehole Tests}

A borehole in the Amargosa Valley (Yucca Mountain, Nevada) was drilled to a total depth of $400 \mathrm{~m}$ using a dual-wall reverse air rotary process to minimize subsurface contamination. The well was fitted with four U-tubes, two installed for permanent (redundant) use at two separate locations (264 mbgs and $348 \mathrm{mbgs}$ ), along with a distributed thermal perturbation sensor (DTPS) (Freifeld et al., 2008b). Sand and bentonite backfill materials were installed after lowering the instrument string in the open borehole strapped onto a 2 " stainless steel piezometer (Fig. 4). Compressed gas cylinders of $\mathrm{N}_{2}$ were used to operate the U-tubes. The initial produced fluid showed significant contamination with suspended bentonite, but after repeated operation, the fluid turbidity dropped. A single outlet valve on the $\mathrm{N}_{2}$ cylinder 


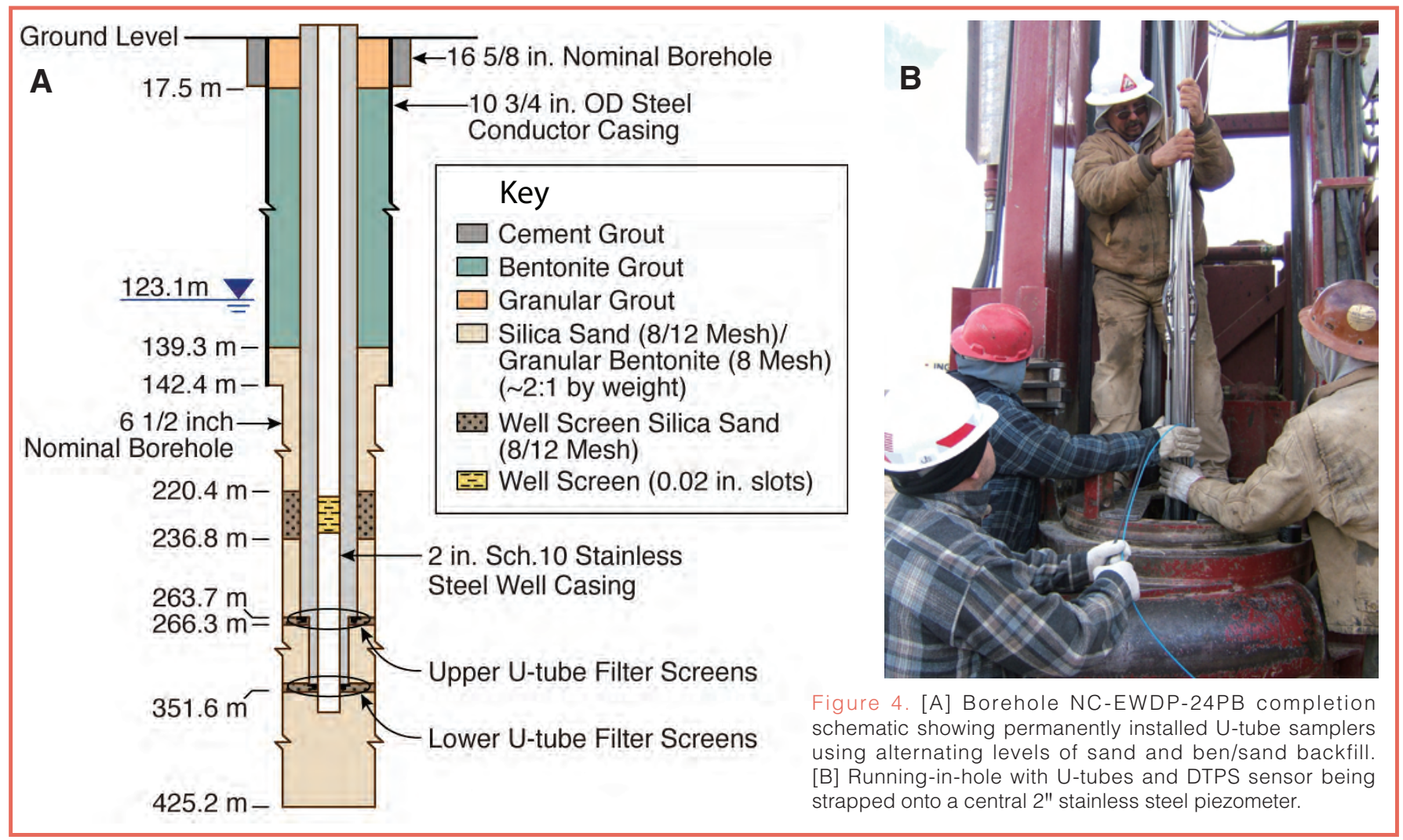

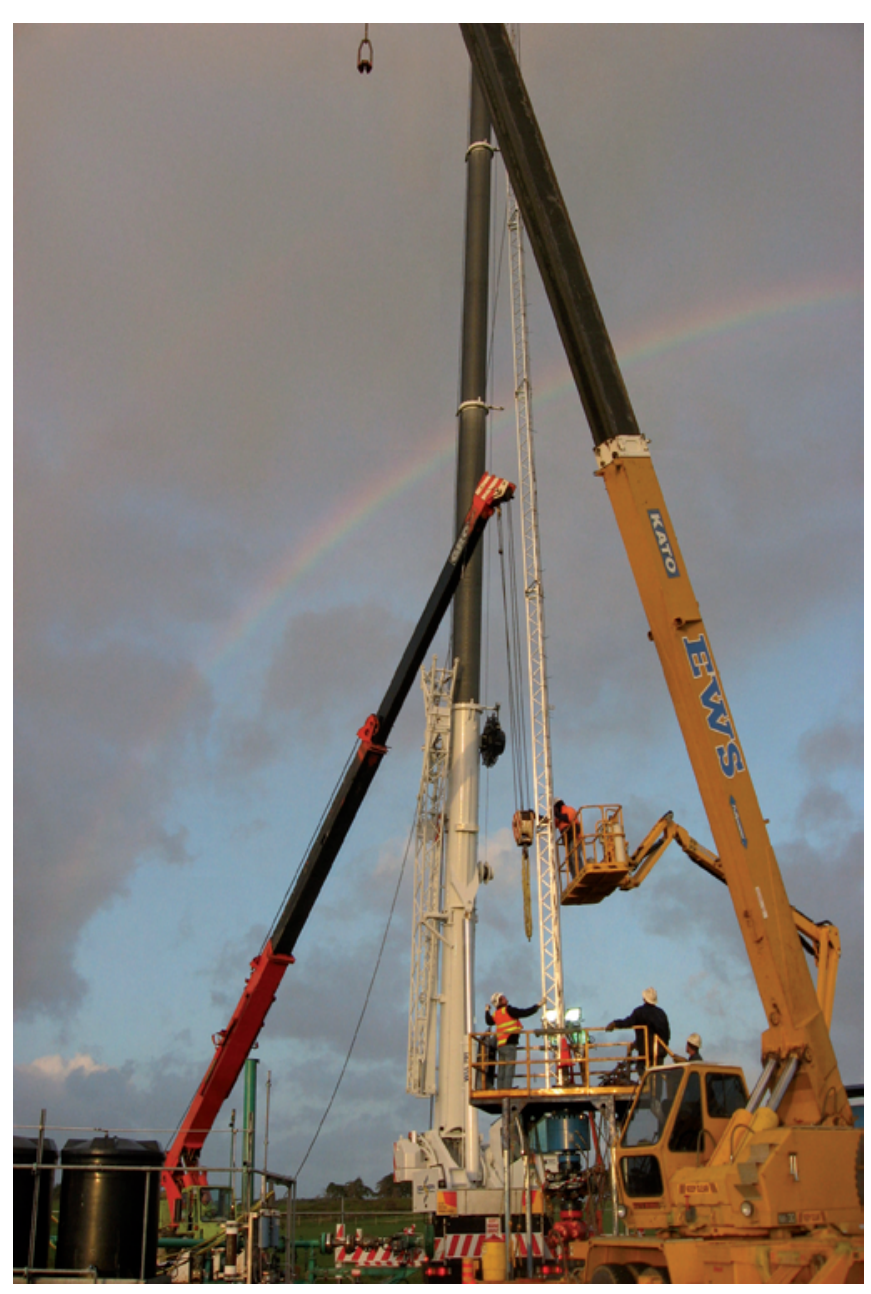

Figure 5. Multi-crane lift deployment of $32 \mathrm{~m}$-long bottomhole assembly consisting of $U$-tubes, seismic sensors, and pressure temperature sensors at the CO2CRC Otway Project Site, Victoria, Australia. pressure regulator controlled the flow of gas to the U-tube drive leg, and a separate valve was on the sample outlet.

The CO2CRC Otway Project (SW of Melbourne, Australia) is a program to demonstrate the storage of $\mathrm{CO}_{2}$ in depleted natural gas formations (Sharma et al., 2007). The project drilled a well $300 \mathrm{~m}$ downdip of a depleted gas well to inject up to $100,000 \mathrm{t}$ of $\mathrm{CO}_{2}$ into the gas-bearing formation and monitor the previous gas well to assess geophysical and geochemical changes induced by injected gas.

The small-diameter casing (31/2") posed the largest challenge to deploying a network of multilevel fluid sampling instruments. To instrument the well, a bottomhole-assembly (BHA) consisting of three U-tubes, two pressure-temperature sensors, and a string of seismic sensors was designed and fabricated. The entire BHA was lifted and installed as one 32 m-long assembly (Fig. 5) and lowered $2 \mathrm{~km}$ using conventional oil field sucker rod. The uppermost U-tube was installed near the top of the gas cap, while U-tube 2 and U-tube 3 were installed $1.5 \mathrm{~m}$ and $6 \mathrm{~m}$ below the gas-water contact, respectively. At the top of the BHA was a custom dual-element, double fixed-end packer. All three U-tubes have been functioning since their initial deployment in October 2007, with weekly sampling operations ongoing. The $\mathrm{CO}_{2}$ injection caused the gas-water contact to be pushed down, and U-tube 2 and U-tube 3 have transitioned from sampling liquids to self-lifting and sampling predominantly gas. One significant hurdle overcome in the operation of the U-tubes was the unexpected presence of natural waxy alkanes in the fluids being produced (Boreham et al., 2008). As the wax traveled up the U-tube sample lines and cooled, it 
coated the U-tube lines, as evidenced by reduced flows, and eventually completely occluded the U-tube 1 sample line. The initial plug was dislodged using a high-pressure piston pump, and a solvent composed primarily of dialkyl- and trialkylbenzenes was used to eliminate future wax build up.

At the High Lake massive sulfide deposit in Nunuvut Territory, Canada, an existing boring was deepened for the purpose of characterizing sub-permafrost microbial communities. A borehole observatory consisting of a U-tube and pressure/temperature sensor was installed beneath a pneumatic packer. The borehole observatory was lowered by hand to a depth of $350 \mathrm{~m}$, using the stainless steel U-tube and packer inflation lines as the strength member. By monitoring the pressure as the sample reservoir chamber filled, we estimated the formation hydraulic conductivity to be $2 \times 10^{-11} \mathrm{~m} \mathrm{~s}^{-1}$ (Freifeld et al., 2008b). Despite heating of the borehole at $20 \mathrm{~W} \mathrm{~m}^{-1}$, the presence of heavily mineralized zones (pyrite $>50 \%$ ) along with temperatures of about $-6^{\circ} \mathrm{C}$ led to the eventual freezing of fluid in the sample tubes. Seven samples were collected prior to the blockage of the tubes. This past summer a U-tube deployment below permafrost near Kangerlussuaq, Greenland used an insulating jacket around the sampling and heater lines to sucessfully prevent freezing while sampling.

\section{Summary and Future Plans}

The U-tube was successful in recovering fluid samples under diverse conditions from depths between $260 \mathrm{~m}$ and $2 \mathrm{~km}$. In all four field deployments presented, the same downhole sampling equipment was used for fluid recovery, despite wide variations in deployment modality. Future plans for U-tube systems include deployments at $\mathrm{CO}_{2}$ storage demonstration sites near Cranfield, Mississippi, at a depth of $3.1 \mathrm{~km}$, along with an installation near Cholla, Arizona. Given the small, unobtrusive size of U-tubes, many other applications are possible, including in extreme environments such as in geothermal fields or subglacial lakes. The ability for U-tubes to provide minimally altered fluids and to be integrated with other measuring devices makes the U-tube an ideal choice for recovery of geofluids.

\section{Acknowledgments}

The field programs were supported by numerous government, industrial, and academic institutions, along with large diverse scientific teams. I would like to thank Susan Hovorka, Robert Trautz, and Paul Cook for making the initial deployment of the U-tube system possible. Funding for Berkeley Lab was provided by the U.S. Department of Energy under Contract No. DE-AC02-05CH11231.

\section{References}

Boreham, C.J., Chen, J., and Hong, Z., 2008. Baseline study on sub-surface petroleum occurrences at the CO2CRC, Otway Project, western Victoria. Poster presented at PESA Eastern Australasian Basins Symposium III, Sydney, 14-17 September, 2008: 489-499.

Freifeld, B.M., and Trautz, R.C., 2006. Real-time quadrupole mass spectrometer analysis of gas in borehole fluid samples acquired using the U-tube sampling methodology. Geofluids 6(3):217-224. doi:10.1111/j.1468-8123.2006.00138.x.

Freifeld, B.M., Chan, E., Onstott, T.C., Pratt, L.M., Johnson, A., Stotler, R., Holden, B., Frape, S., Pfiffner, S.M., DiFurio, S., Ruskeeniemi, T., and Neill, I., 2008b. Deployment of a deep borehole observatory at the High Lake Project Site, Nunavut, Canada. Proc. Ninth Intl. Conf. on Permafrost, LBNL-78E, Fairbanks, Alaska, U.S.A., 29 June-3 July 2008.

Freifeld, B.M., Finsterle, S., Onstott, T.C., Toole P., and Pratt, L.M., 2008a. Ground surface temperature reconstructions: using in situ estimates for thermal conductivity acquired with a fiber-optic distributed thermal perturbation sensor, Geophys. Res. Lett., 35:L14309, doi:10.1029/2008GL034762.

Freifeld, B.M., Trautz, R.C., Yousif, K.K., Phelps, T.J., Myer, L.R., Hovorka, S.D., and Collins, D., 2005. The U-Tube: A novel system for acquiring borehole fluid samples from a deep geologic $\mathrm{CO}_{2}$ sequestration experiment. J. Geophys. Res., 110:B10203, doi:10.1029/2005JB003735.

Hovorka, S.D., Benson, S.M., Doughty, C., Freifeld, B.M., Sakurai, S., Daley, T.M., Kharaka, Y.K., Holtz, M.H., Trautz, R.C., Nance, H.S., Myer, L.R., and Knauss, K.G., 2006. Measuring permanence of $\mathrm{CO}_{2}$ storage in saline formations: the Frio experiment: Environ. Geosci., 13:105-121 doi:10.1306/eg. 11210505011.

Kharaka, Y.K., Cole D.R., Hovorka S.D., Gunter W.D., Knauss K.G., and Freifeld, B.M., 2006. Gas-water-rock interactions in Frio Formation following $\mathrm{CO}_{2}$ injection: Implications for the storage of greenhouse gases in sedimentary basins. Geology: 34(7):577-580 doi:10.1130/G22357.1.

Sharma, S., Cook, P., Berly, T. and Anderson, C., 2007. Australia's first geosequestration demonstration project - the CO2CRC Otway Basin Pilot Project. APPEA J., 47(1): 257-268.

Wood, W., 1973. A technique using porous cups for water sampling at any depth in the unsaturated zone. Water Resour. Res., 9(2): 486-488, doi:10.1029/WR009i002p00486.

\section{Author}

Barry M. Freifeld, Earth Sciences Division, Lawrence Berkeley National Laboratory, MS 90-1116, One Cyclotron Road, Berkeley, Calif. 94720, U.S.A., e-mail: BMFreifeld@ lbl.gov. 